Dana R. Stojiljković , Marko Mihić, Dragan Bjelica

\title{
Performance Analysis of Indie Gaming Projects on Crowdfunding Platforms: Evidence from Kickstarter.com
}

DOI: 10.7595/management.fon.2021.0035

\begin{abstract}
:
Research question: The aim of this paper is to examine the financial success of projects in game development industry in comparison with to projects in other industries hosted on crowdfunding platform Kickstarter.com. Motivation: We live in the world of technology where companies arise and disappear on daily basis. The traditional way of financing was expanded with alternative online platforms. Our goal was to conduct an empirical analysis of one crowdfunding platform (Kickstarter.com) in order to understand if technology projects are doing better than other projects. If they do, what are the key factors for their success? Idea: Our goal was to better understand how crowdfunding model supports small indie development projects and projects in other industries. Data: We used the data of 148.510 companies applied for crowdfunding financing between 2015 and 2020, published on the web crawler platform Web Robots. Tools: All statistical analyses were performed using statistical software IBM ${ }^{\circledR}$ SPSS $®$ Statistics v.21. The data were presented using standard methods of non-parametric descriptive statistics (absolute and relative frequencies for medians and interquartile ranges for numeric outcomes). For testing of statistical significance of difference between two groups we used the Pearson's Chi-Quadrat test and Mann-Whitney test, where appropriate. The effect size for the $2 \times 2$ analyses was estimated using Odds ratios. Findings: The paper analyses the financial success of gaming and not gaming projects and tries to identify key factors for successful funding. We found a statistically significant higher prevalence of successful financing in game development projects, with 2.3 times higher odds of successful funding compared to not-gaming industry. Our analysis of quantitative indicators such as the number of backers, goal amount, pledged amount, pledged amount per backer and pledged to goal ratio also showed that projects in game development statistically outperformed projects in other categories. Promising game projects were supported by three times more backers on average and attained almost as double funds as other projects, while still sporting more modest pledged amounts per backer. These findings support the notion of crowdfunding being a viable modality of financing independent game development in emerging economies. Contribution: This paper expands the existing research related to the crowdfunding platforms and indie development companies and formulates key factors for successful financing for technology startup firms.
\end{abstract}

Keywords: crowdfunding platforms, game-development industry, Kickstarter.com, financial performance, factors of success.

JEL classification: O22, M13.

\section{Introduction}

Video gaming industry supported by strong technology development and various alternative financing models is becoming one of the main entertainment industries. A growing number of online platforms underpinning projects in various industries suggest that small companies/teams are able to hold up their creative projects without classical capital providers.

The aim of this paper was to examine the performance of game-development crowdfunding projects compared to other projects, not related to games. We also discussed potential factors in game development in- 
dustry that may have contributed to its financial success. We analyzed 148.510 companies that applied for funding on the platform Kickstarter.com in the time period between 1.1.2015 and 31.12.2020.

There is not too much literature devoted to financing of indie gaming projects on crowdfunding platforms. Many research questions need to be answered. What is the prevalence for positive financing of gaming versus non-gaming projects? What is the impact of number of backers, goal amount, pledged amount, pledged amount per backer and pledged to goal ratio in the group of successfully/unsuccessfully financed projects on Kickstarter.com? What is the impact of goal amount and pledged amount per backer in the group of gaming/non-gaming financed projects on Kickstarter.com? Which factors contributed to success in crowdfunding of gaming projects?

We begin our study by describing the historical setting of video games industry and crowdfunding as an alternative model of financing. Then we present a comprehensive literature review about the impact and scope of online investment platforms for startup projects. Later we describe our methodology of empirical research followed by the results received. We then conclude with recommendations for academics and researchers.

\section{Literature Background}

From its humble beginnings and the video game Tennis for Two designed by the physicist William Alfred Higginbotham onward (Nyitray, 2011), the video game has represented a novel medium for design and a vigorous force driving the development of computer technology. Over the last decades it has become a major part of entertainment industry featuring constant growth and innovation. The value of the video games market worldwide has increased significantly and is forecast to grow even further in the upcoming years, surpassing the 200 billion U.S. dollars mark in 2023 (Statista, 2021). As of today, there are over 2.7 billion gamers worldwide (Statista, 2021).

Two main modes of organization practices and production structures have developed across the gaming industry: the "indie" and the "AAA" games. AAA games are developed by large studios with a massive production and marketing budgets, mostly backed by a strong publisher agency (Engelstatter \& Ward, 2016). It is also quite common that publishing agencies finance complete game development, paying video game developers royalties and thus having much say in all segments of the production process (Maximumgames, 2016). Boasting considerable budgets, these video games tend to be larger in scope, well-polished and feature-detailed, with realistic high-quality graphics and usually more hardware demanding. On the other hand, creative independent development teams tend to produce games without much interference from larger corporate structures (Williams, 2009). Indie games tend to be of smaller scope, shorter, featuring a more focused game play, more stylized art designs and having comparatively modest production budgets. Nonetheless there are many examples of extremely successful indie games like World of Goo, Minecraft, and Fez, to name a few (Computer Hope, 2017). Independent game developers have managed to gain an increased access to the mass gaming market and digital distribution through third-party online gaming retailers such as Valve's Steam platform (Lin, Bezemer \& Hassan, 2017). This platform provides distribution services to more than $47 \%$ of game publishers (Businesswire, 2021). The platform's number of concurrent users peaked in May 2021 at 26.85 million (Statista, 2021). Another major factor of development is technological progression of gaming platforms and simplified usage of development tools which induced that most innovations tend to come from individual designers in the form of indie companies.

Due to global epidemic in 2019/2020 and imposed social distances, video games such as New Horizons provided some benefits and spiritual comfort to their fans (Zhu, 2021). Some authors in behaviour sciences proposed that online gaming in general could be a healthy coping strategy for the majority to overcome protracted periods of social isolation (King, Delfabbro, Billeux, \& Potenza, 2021). According to Steam game trends, 2020 was the year when gaming became a truly mainstream and socially acceptable pastime (Indie to indie games, 2020). In 2020, 9,866 games released on Steam, more than any other year in the past. That is $24,4 \%$ more than the 7,930 in 2019 . The big increase in new game releases has exclusively come from indie developers, due to smaller, more manageable teams and shorter development schedules. Comparing the numbers of games released in 2019 and 2020, Steam reported a decrease of big budget AAA-games and medium-sized budget games releases by $20.5 \%$ and $10.9 \%$, respectively. Conversely, indie games saw a $25.6 \%$ increase in number published, as well as a nearly $20 \%$ increase in the average price per copy in the same time interval (Indie to indie games, 2020). A significant improvement also came from average ratings of indie games. The indie games released in 2020 received on average $78 \%$ positive reviews in comparison with 74\% in 2019 (Indie to indie games, 2020). These data show that indie games have also improved 
their quality. Mobile gaming has also supported rapid growth of the global video gaming market (Statista, 2021). It simplified the customer access to video games since they could be instantly purchased and tried out. It has also opened new markets for casual players (Feijoo, Gomez-Barroso, Aguado \& Ramos, 2012). In 2020 smartphone games accounted for almost 50 percent of video gaming revenue worldwide (Statista, 2021). Mobile games revenue is on track to surpass the 100 billion-dollar-mark by 2023 (Statista, 2021). One of the most interesting aspects of gaming industry is the establishing of eSports as organized video gaming championships, in which professional and amateur players compete against one another (Statista, 2021). The rapidly growing phenomenon of eSports as an intersection of gaming and sports offers an innovative wave of branding opportunities, engaging content, and activation for millions across the globe (Statista, 2021).

In the business life of an average company/project various indicators are used in order to measure the current status and future potentials. The challenge is to group them together and extract a sensible performance measure for adequate decision-making processes (Franceschini, Galetto \& Maisano, 2007). Currently, there are several different approaches for developing such an integrative system: 1) the Balanced Scorecard method (Kaplan \& Norton, 1996); 2) the Strategic Profit Impact model, also known as the Dupont model (Lambert \& Burduroglu, 2021); 3) the Critical Few method (Performance Based Management Special Interest Group, 2001); 4) the models EFQM (European Foundation for Quality Management, 2021) and Malcom Baldrige Quality Award (Malcom Baldrige Quality Award, 2021). Each of these major systems has strengths and weaknesses and is used for different purposes. They represent measures of individual relationships connecting various causal variables to various performance measures (Capon, Farley \& Hoenig, 1990). Reviews of the financial performance literature have tended to be qualitative in nature (Capon, et al., 1990). Quantitative comparison of results from different studies is difficult, since model specifications and operationalizations of explanatory and dependent variables differ widely lacking tradition of systematic replication in order to quantify specific effects of particular causal variables in a wide number of situations (Capon, et al., 1990). For the reasons mentioned above, key performance indicators for individual company/projects are mostly adapted versions of already established theoretical models which try to provide optimal information of current performance and future actions (Franceschini et al., 2007).

Crowdfunding as a process of raising money from a broad group of people through an open call on various internet platforms provides financial support to talented individuals and their business ideas (Bouncken, Komorek \& Kraus, 2015). The Kickstarter.com, a general crowdfunding platform, supports a range of projects such as video gaming development, photography, design, journalism etc. Well-known companies such as Oculus VR, Popsocket, Allbirds etc. were initially financed via "crowd funders" and this model constantly shows great potential for future growth. In 2019, it amounted at the global crowdfunding market to ca. USD 14.2 billion and is projected to double this amount by 2025 (Crowdfunding Market, 2020). This model of financing lends itself very well to all kinds of independent product development, including video games. Creating, measuring, and managing performance indicators in gaming projects on Kickstarter.com is crucial for successful financing. The most important indicators are count of backers, project goal amount, project pledged amount, industry branch, current financing status and fundraising deadline (Kickstarter, 2021). A project leader is responsible for setting a realistic financial goal and the time-scope of the fundraising campaign (Lax, 2017). Funding on Kickstarter.com is defined as "all-or-nothing" model, which means that a project needs to achieve financial goal and time deadline in order that pledgers be charged (Kickstarter, 2021). The main idea is to protect developers and minimize risk for pledgers, so that developers have enough resources to finish their work. They are not expected to complete a project without the funds necessary to do so (Kickstarter, 2021). On the other hand, pledgers are also well informed, and they are only funding creative ideas that are set to succeed. According to Kickstarter.com, once a creator launches their project, the funding goal and deadline are locked in and cannot be changed. A standard platform fee amounts $5 \%$ for successfully financed projects. The funds are usually employed for research and development, manufacturing, packaging and/or labor costs (Kickstarter, 2021). A study conducted by (Lee \& Chiravuri, 2019) confirmed the importance of proper managing of performance indicators and showed that serial creators with positive initial crowdfunding are more likely to explore a new industry or product category in the crowdfunding market and to set a higher target capital for the subsequent campaign when they change a project category. Another study (Roma, Petruzzelli, \& Perrone, 2017) from a sample of technology projects launched on Kickstarter demonstrate that pledging a higher amount of money in crowdfunding can increase investors trust and provide subsequent funding if complemented by the presence of patents or a large network of social ties. 


\section{Methods}

For our empirical analysis, we used data from Kickstarter.com hosted on web crawler platform Webrobots.io. We analyzed 148.510 companies, which applied to the Kickstarter.com funding in the time period between $1 / 1 / 2015$ and 31/12/2020. For every project we tracked specific project indicators such as project id, project name, count of backers, country, year of launch, current state of project, goal amount in USD, pledged amount in USD and industry branch.

All projects were divided into two groups based on industry: game development projects and other projects. Game development projects represent all projects connected to board and video games development. Other projects included art, comics, crafts, dance, design, fashion, film \& video, food, journalism, music, photography, publishing, technology, and theatre.

Our primary outcome variable was the fundraising outcome. The data source defined four possible financing outcomes: successful, cancelled, failed and live financing.

Successful financing means that the project reached both its financial goal and fundraising deadline $(52 \%$ of all projects). Some $41 \%$ projects failed to amass the goal amount by the fundraising deadline. Five percent of projects were cancelled prior to fundraising campaign launch for reasons such as deadline and/or the financial goal not being realistic. Lastly, $2 \%$ of projects were "Live", meaning currently in the process of fundraising. Since their end status had yet to be determined, they were excluded from the statistical analysis. We subsumed the cancelled and failed projects in the group named "unsuccessful financing", thus making fundraising outcome effectively a dichotomous variable i.e., successful and unsuccessful projects.

Our secondary outcome variables were the number of backers, goal amount, pledged amount, pledged amount per backer and pledged to goal ratio.

Backers are individuals who pledge money to join creators in bringing projects to life, i.e., to support a creative process. They receive various rewards for their engagement as a creator's way to share a piece of project with their backer community (Kickstarter, 2021). The more backers a project receives, the more chances it has to hit its goal amount and fundraising deadline.

The goal amount is the amount of money creators are setting on Kickstarter.com. According to Kickstarter.com, once a creator launches their project, the funding goal and deadline are locked in and cannot be changed.

The pledged amount represents the amount of money a specific project received from its backers. Only projects whose pledged amount hits or overachieves their goal amount within a specific deadline will be successfully financed (Kickstarter, 2021).

Based on our secondary outcome variables, we calculated two additional variables: average pledged amount per backer as well as pledged-to-goal ratio. They represent a fair measure of project success, relatively independent from its specific scope.

We tested for differences between the groups of game development and other projects in terms of our primary outcome variable (financing outcome) across the whole sample, as well as on per year basis. In order to control the confounding influence of differences in financing outcome on the secondary outcomes, we stratified the research groups by financing outcome (successfully and not successfully financed projects) and performed a separate statistical comparison of the groups in each stratum. In addition, we stratified the research groups based on industry: game development and other projects and performed a separate statistical comparison of the groups in each stratum.

All statistical analyses were performed using statistical software IBM ${ }^{\circledR}$ SPSS $®$ Statistics v.21. The data were presented using standard methods of non-parametric descriptive statistics (absolute and relative frequencies for medians and interquartile ranges for numeric outcomes). For testing the statistical significance of difference between two groups we used the Pearson's Chi-Quadrat test and Mann-Whitney test, where appropriate. The effect size for the $2 \times 2$ analyses was estimated using Odds ratios. 


\section{Results}

We analyzed 148,510 projects in fifteen different industries, which applied to the Kickstarter.com funding in the time period between $1 / 1 / 2015$ and 31/12/2020. Projects were located in the USA and Canada (69\%), Europe (24\%), the Far East (3\%), Australia (2\%) and Mexico (2\%).

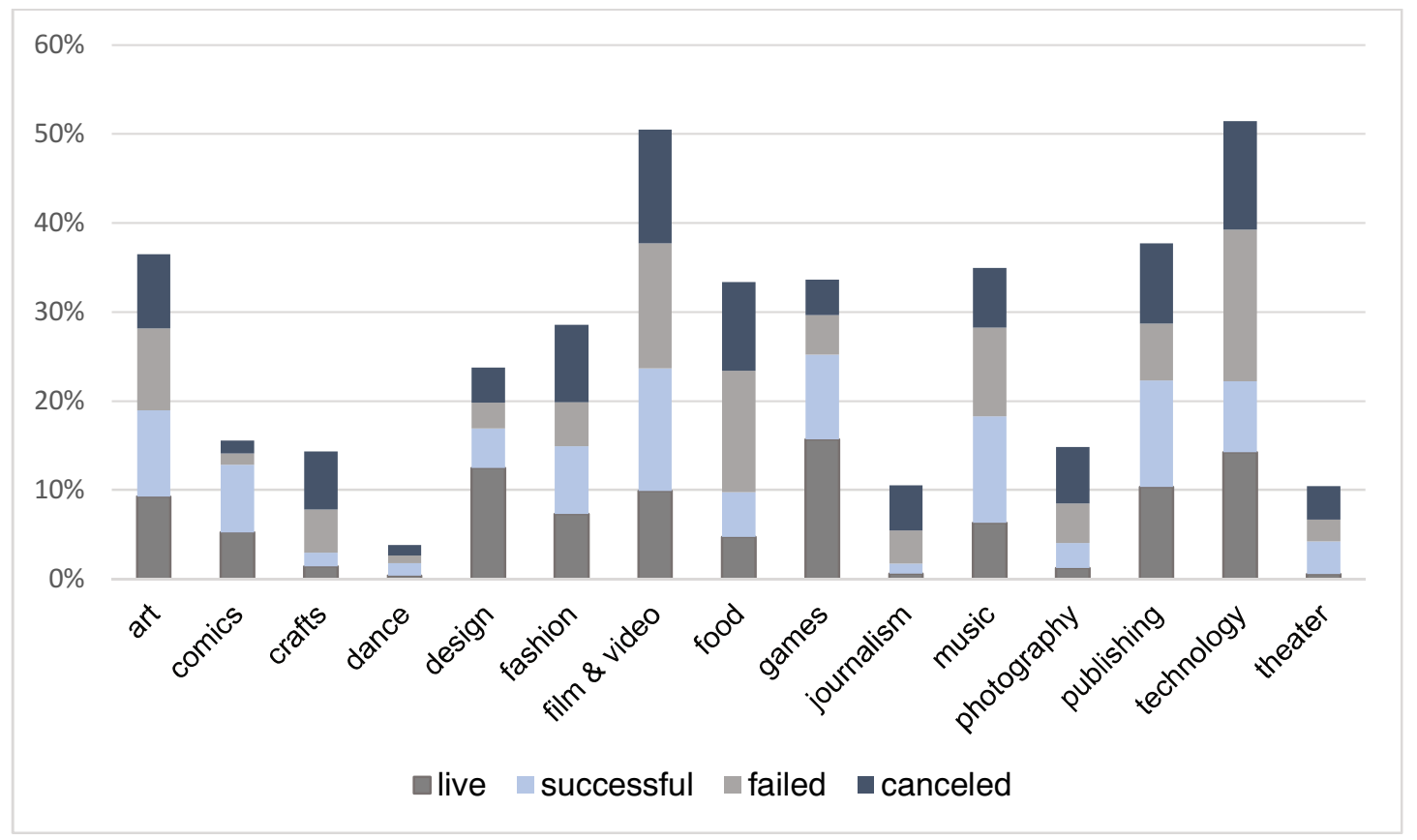

Figure 1. Financing status of projects per industry

Table 1 presents the comparison of frequency of successfully financed projects in gaming industry with projects from non-gaming industry. Out of a total of 145,583 projects assessed, $71 \%$ projects in gaming industry met their financing goals in comparison with $51.5 \%$ projects in non-gaming industry. This difference was statistically highly significant, $\mathrm{X} 2(1)=1466.5, \mathrm{p}<.001$. Projects in the gaming industry are 2.3 times more likely to be successfully financed than those in the non-gaming industry.

Table 1: Comparison of frequency of successfully financed projects in gaming and non-gaming industry

\begin{tabular}{|l|c|c|c|c|}
\hline & & Gaming industry & Non-gaming industry & Total \\
\hline \multirow{2}{*}{ Successful } & Frequency & 7,322 & 69,614 & 76,936 \\
& Percent & $71 \%$ & $51 \%$ & \\
Cancelled / Failed & Frequency & 2,992 & 65,655 & 68,647 \\
& Percent & $29 \%$ & $49 \%$ & \\
Total & Frequency & 10,314 & 135,269 & 145,583 \\
& Percent & $100 \%$ & $100 \%$ & $100 \%$ \\
\hline
\end{tabular}


Table 2: Yearly odds ratio for game development projects

\begin{tabular}{|c|c|c|c|c|c|c|c|}
\hline & & \multicolumn{4}{|c|}{ Status } & \multirow{3}{*}{$\begin{array}{c}\begin{array}{c}\text { Pearson } \\
\text { Chi-Square }\end{array} \\
x^{2}(\mathrm{df}=1) \\
\end{array}$} & \multirow{3}{*}{$\begin{array}{c}\text { Odds } \\
\text { Ratio } \\
\text { OR }\end{array}$} \\
\hline & & \multicolumn{2}{|c|}{ Successful } & \multicolumn{2}{|c|}{ Cancelled / Failed } & & \\
\hline & & Frequency & Percent & Frequency & Percent & & \\
\hline \multirow{2}{*}{2015} & gaming industry & 754 & $46.70 \%$ & 862 & $53.30 \%$ & \multirow{2}{*}{16.590} & \multirow{2}{*}{1.231} \\
\hline & $\begin{array}{l}\text { non-gaming } \\
\text { industry }\end{array}$ & 12,853 & $41.50 \%$ & 18,094 & $58.50 \%$ & & \\
\hline \multirow[b]{2}{*}{2016} & gaming industry & 782 & $55.10 \%$ & 638 & $44.90 \%$ & \multirow[b]{2}{*}{54.719} & \multirow[b]{2}{*}{1.498} \\
\hline & $\begin{array}{l}\text { non-gaming } \\
\text { industry }\end{array}$ & 10,630 & $45.00 \%$ & 12,990 & $55.00 \%$ & & \\
\hline \multirow[b]{2}{*}{2017} & gaming industry & 790 & $61.20 \%$ & 500 & $38.80 \%$ & \multirow[b]{2}{*}{89.056} & \multirow[b]{2}{*}{1.730} \\
\hline & $\begin{array}{l}\text { non-gaming } \\
\text { industry }\end{array}$ & 10,488 & $47.70 \%$ & 11,486 & $52.30 \%$ & & \\
\hline \multirow[b]{2}{*}{2018} & gaming industry & 859 & $71.10 \%$ & 350 & $28.90 \%$ & \multirow[b]{2}{*}{119.561} & \multirow[b]{2}{*}{2.011} \\
\hline & $\begin{array}{l}\text { non-gaming } \\
\text { industry }\end{array}$ & 10,874 & $55.00 \%$ & 8,909 & $45.00 \%$ & & \\
\hline \multirow[b]{2}{*}{2019} & gaming industry & 896 & $73.40 \%$ & 325 & $26.60 \%$ & \multirow[b]{2}{*}{86.601} & \multirow[b]{2}{*}{1.838} \\
\hline & $\begin{array}{l}\text { non-gaming } \\
\text { industry }\end{array}$ & 12,298 & $60.00 \%$ & 8,200 & $40.00 \%$ & & \\
\hline \multirow[b]{2}{*}{2020} & gaming industry & 3,241 & $91.10 \%$ & 317 & $8.90 \%$ & \multirow[b]{2}{*}{805.717} & \multirow[b]{2}{*}{4.899} \\
\hline & $\begin{array}{l}\text { non-gaming } \\
\text { industry }\end{array}$ & 12,471 & $67.60 \%$ & 5,976 & $32.40 \%$ & & \\
\hline
\end{tabular}

Table 2 presents a yearly odds ratio for game development projects to be successfully financed in comparison with other projects. The two groups (projects) were compared in terms of the number of backers, the goal amount, the pledged amount, the pledged amount per backer and the pledged goal ratio, stratified by the primary financial outcome. The gaming projects significantly outperformed the non-gaming projects in all categories. These results follow a positive trend from 2015 onwards suggesting dramatic growth potential of this market and high performance of active projects, especially in 2020. Only in 2019 the line did not follow a linear trend (Odds ratio 1.838). This could be due to the fact that many campaigns were postponed from 2019 to 2020. This positive trend is also graphically given in Figure 2, which represents the yearly trend in odds ratios of successful project financing in game development industry in comparison to projects in other industry branches.

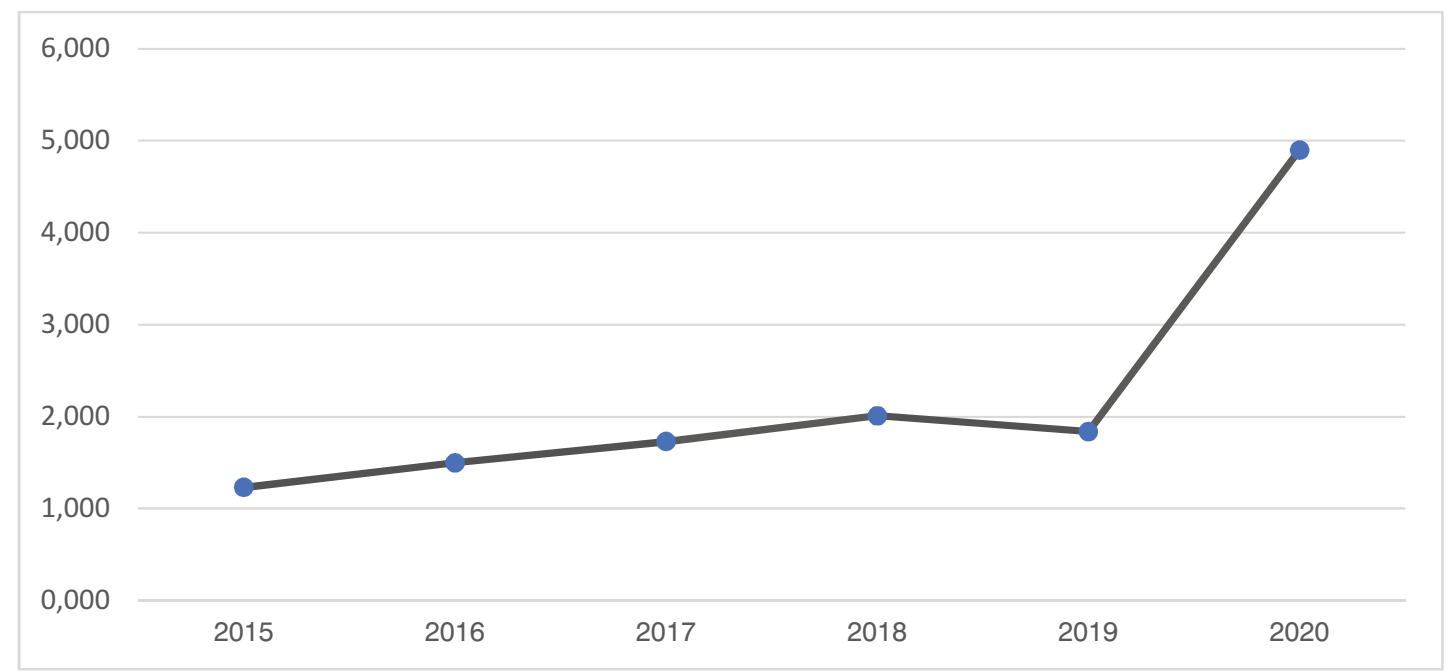

Figure 2. Yearly trend in odds ratios of successful project financing in game industry

Table 3 presents these comparisons within the stratum of projects which were successfully funded, whereas Table 4 shows these among unsuccessfully financed projects. 
Table 3: Comparisons within the stratum of projects which were successfully funded

\begin{tabular}{|c|c|c|c|c|c|c|c|c|}
\hline & \multicolumn{6}{|c|}{ Status successful } & \multirow{2}{*}{\multicolumn{2}{|c|}{ Mann-Whitney }} \\
\hline & \multicolumn{3}{|c|}{ Games } & \multicolumn{3}{|c|}{ Non-games } & & \\
\hline & Median & & & Median & & & $Z_{U}$ & $\mathbf{p}$ \\
\hline Number of backers & 211 & 72 & 545 & 70 & 32 & 163 & -54.60 & $<.001$ \\
\hline Goal amount (in USD) & 4497 & 1000 & 10159 & 3414 & 1000 & 10000 & -8.10 & $<.001$ \\
\hline Pledged amount (in USD) & 9410 & 2965 & 26257 & 5011 & 1731 & 13420 & -28.70 & $<.001$ \\
\hline Pledged amount per backer & 41.78 & 28.58 & 64.82 & 62.43 & 38.52 & 106.14 & -44.30 & $<.001$ \\
\hline Pledged to Goal Ratio & 1.89 & 1.21 & 4.27 & 1.21 & 1.05 & 1.95 & -47.70 & $<.001$ \\
\hline
\end{tabular}

The median number of backers in group games was three times larger than in other projects. The median goal amount in group games was 1.3 times greater than in other projects. The median pledged amount in group games was almost two times higher comparing to other projects. On the other hand, the median pledged amount per backer in group games was $30 \%$ lower compared to non-gaming projects. The median pledged to goal ratio in group games was 1,6 higher than in the other projects. The difference in all categories was statistically significant.

Table 4: Comparisons within the stratum of projects which were unsuccessfully funded

\begin{tabular}{|c|c|c|c|c|c|c|c|c|}
\hline & \multicolumn{6}{|c|}{ Status unsuccessful } & \multirow{2}{*}{\multicolumn{2}{|c|}{ Mann-Whitney }} \\
\hline & \multicolumn{3}{|c|}{ Games } & \multicolumn{3}{|c|}{ Non-games } & & \\
\hline & Median & \multicolumn{2}{|c|}{ IQR } & Median & \multicolumn{2}{|c|}{ IQR } & $\mathbf{Z u}$ & $\mathbf{p}$ \\
\hline Number of backers & 3 & 1 & 9 & 3 & 1 & 8 & -1.60 & 0.11 \\
\hline Goal amount (in USD) & 10,000 & 3,000 & 30,000 & 7,500 & 2,500 & 25,000 & -6.94 & $<0.001$ \\
\hline Pledged amount (in USD) & 42 & 1 & 399 & 54 & 1 & 439 & -1.43 & 0.15 \\
\hline $\begin{array}{l}\text { Pledged amount per } \\
\text { backer }\end{array}$ & 22.25 & 5.5 & 55.83 & 27.97 & 8.24 & 62.5 & -5.96 & $<0.001$ \\
\hline Pledged to Goal Ratio & $5.0 \times 10^{-3}$ & 0 & 0.06 & $8.7 \times 10^{-3}$ & 0 & 0.08 & -4.29 & $<0.001$ \\
\hline
\end{tabular}

The median number of backers in both groups was 3 and the difference was statistically insignificant $\left(Z_{U}=-\right.$ $1.6 ; p<0.001)$. The median goal amount in group games was 1.3 times higher than in non-gaming projects. The difference was statistically significant $\left(Z_{U}=-6.9 ; p<0.001\right)$. The median pledged amount in group games was $20 \%$ lower than in the non-gaming group. The difference was statistically insignificant. $\left(Z_{U}=-1.4\right.$; $p<0.001)$. The median pledged amount per backer in group games was also $20 \%$ lower comparing to the non-gaming group. The difference was statistically significant. $\left(Z_{U}=-6.0 ; p<0.001\right)$. The median pledged to goal ratio in both groups was less than 0.01 . The difference was statistically significant. $\left(Z_{U}=-4.3 ; p<0.001\right)$.

The two groups were compared in terms of goal amount and pledged amount per backer, stratified by the industry. Table 5 presents these comparisons within the stratum of projects in gaming industry, whereas Table 6 shows these among non-gaming projects.

Table 5: Comparison within the stratum of gaming development projects

\begin{tabular}{|c|c|c|c|c|c|c|c|c|}
\hline & \multicolumn{6}{|c|}{ Games } & \multirow{2}{*}{\multicolumn{2}{|c|}{ Mann-Whitney }} \\
\hline & \multicolumn{3}{|c|}{ Successful } & \multicolumn{3}{|c|}{ Cancelled or failed } & & \\
\hline & Median & & & Median & & & $\mathbf{z}_{u}$ & $\mathbf{p}$ \\
\hline Goal amount (in USD) & 4497 & 1000 & 10159 & 10000 & 3000 & 30000 & -24.46 & $<0.001$ \\
\hline Pledged amount per backer & 41.78 & 28.58 & 64.82 & 22.25 & 5.5 & 55.83 & -25.31 & $<0.001$ \\
\hline
\end{tabular}

The median goal amount in successful projects was twice lower than in the cancelled/failed group. The difference was statistically significant $\left(Z_{U}=-24,5 ; p<0.001\right)$. The median pledged amount per backer in successful projects was twice greater than in cancelled/filled group. The difference was statistically significant $\left(Z_{U}=-25,3 ; p<0.001\right)$ 
Table 6: Comparison within the stratum of other projects

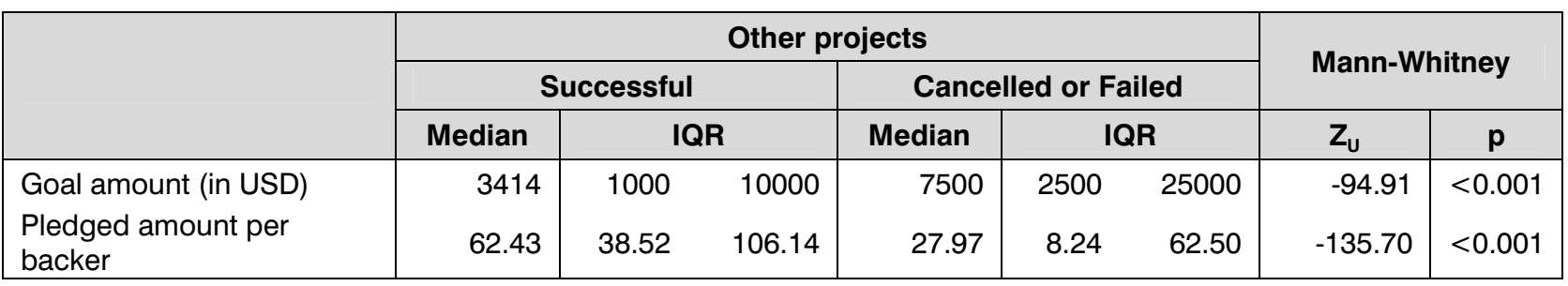

The median goal amount in successful projects was twice lower than in the cancelled/failed group. The difference was statistically significant $\left(Z_{U}=-94.9 ; p<0.001\right)$; the median pledged amount per backer in successful projects was almost three times higher than in the cancelled/failed group. The difference was statistically significant $\left(Z_{U}=-135.7 ; p<0.001\right)$.

\section{Discussion}

Research question 1: What is the prevalence for positive financing of gaming versus non-gaming projects? In this study, we provide empirical evidence on the relationship of projects successful financing in gaming and non-gaming industries. In our research, we found a $71 \%$ prevalence of successful financing in gaming industry projects, with 2.3 times higher odds of success compared to the not-gaming industry. This analysis was also separated on a yearly basis and showed positive trends from 2015 onwards. Only in 2019 the line did not follow a linear trend (Odds ratio 1.838). This could be due to the fact that many campaigns were postponed from 2019 to 2020. Similar results were received (Hadzinsky, 2014) analyzing 20 crowdfunded gaming campaigns on Kickstarter.com. Out of the 20 campaigns 12 were successful, while the remaining eight either failed or were cancelled, giving a success rate of $60 \%$. He concluded that a crowdfunding gaming project will succeed more often than it will fail. Our results indicate that there are many factors to be discussed in order to understand the success in crowdfunding of gaming projects.

Research question 2: What is the impact of the number of backers, goal amount, pledged amount, pledged amount per backer and pledged to goal ratio in the group of successfully/unsuccessfully financed projects on Kickstarter.com? The number of backers in a group of successful projects is 3 times higher in the gaming than in the nont-gaming field. In the stratum of unsuccessful projects, the number of backers is similar in both fields with no statistically significant difference. This indicates that gamers as main pledgers are critical in supporting crowdfunding projects. It is not clear if there are some additional factors other than quality of the product, which motivates backers to support. In a study of crowdfunding financing (Du, Li \& Wanga, 2019) analyzed how the number of options in reward-based crowdfunding projects can be used to support the success of the projects. They found that the number of options could have an inverted U-shaped impact on the chance of having a successful crowdfunding project. An additional study on the dynamics of crowdfunding conducted by Kuppuswamy \& Bayus showed that additional backer support is negatively connected to its past backer support. Many potential backers do not contribute to a project that has already received a lot of support because they expect that other supporters will provide the additional funding. They showed that the diffusion of responsibility effects diminish, as the project funding approaches its closing date (Kuppuswamy \& Bayus, 2013).

The median goal amount in group gaming projects was 1.3 times greater than in other projects. This is true for both strata, i.e., for successful and unsuccessful projects and could be explained with increasing scale and complexity of projects which then increase the development costs (Bosch \& Sijtsema, 2010). More interesting is that unsuccessful projects have 2.2 times higher goal amounts in comparison with successful projects, independent of the industry. It indicates that setting unrealistic goal amounts could be a significant predictor of financing issues in both industries. Setting a meaningful goal is important so that backers get tangible value for their support and so to propel the campaign faster (Hadzinsky, 2014).

New research also shows that with an increasing number of crowdfunding platforms, fewer projects are able to achieve successful funding. This affected the number of backers to be reduced, higher goal amount increased and shorter duration to meet the funding goal increased the likelihood of achieving the funding goal. The results suggest that over time crowdfunding platforms increase reliance on costlier signals such as higher goal amount and shorter duration and reduce reliance on noisier signals, i.e., number of backers (Devaraj \& Patel, 2016).

In successfully financed projects the data indicates that the pledged amount is almost twice higher in gaming compared to non-gaming projects. This could be explained by the fact that many other industries such 
as photography, journalism or music are not cost intensive as gaming development and hence their goal amounts were initially lower (Bosch \& Sijtsema, 2010). In unsuccessfully financed projects this difference was not statistically significant. It is probably due to the backers' dynamics so that many backers never came back to support specific projects if the final call and a project per se was not effective enough (Kuppuswamy \& Bayus, 2013).

The pledged amount per backer is significantly lower at successfully and unsuccessfully gaming projects than in other projects. This ratio could be explained as correlation of value a specific project receives from a backer. Since gaming projects have statistically significant higher number of backers, it is to expect that a pledged amount per backer would be relatively low.

Considering that gaming projects have much higher goal amounts, calculated pledged-to-goal ratio aimed to standardize pledged amounts and scope of a specific project. This ratio was in gaming projects $50 \%$ higher than in non-gaming projects which points out an increasing readiness of investors/pledgers to finance gaming development compared to other projects. An additional factor which may support these results is that crowdfunding was primarily considered as a funding mechanism for game development due to known issues they face on alternative funding markets and IT skills their backers possess (Nuciarelli, Li \& Fernandes, 2016).

Research question 3: What is the impact of the goal amount and the pledged amount per backer in the group of gaming/non-gaming financed projects on Kickstarter.com? In order to analyze gaming and not gaming projects separately, we stratified the research groups based on industry. The two groups were compared in terms of goal amount and pledged amount per backer. The results showed that in gaming and other projects the goal amount was twice lower in successful than in unsuccessful projects, which confirms that setting unrealistic goal amounts is very often connected with financing issues. The second indicator, Pledged amount per backer was in both groups twice higher in successful projects which is to be expected, since those projects successfully entered their final finance phase.

Research question 4: Which factors contributed to success in crowdfunding of gaming projects? Many authors recognized various factors of success of gaming projects in crowdfunding. (Lax, 2017) described setting a realistic goal amount, providing attractive rewards to backers, using appropriate and informative materials in crowdfunding campaigns, open communication between team and supporters and flexible rewarding system as key parts in successful financing. Our analysis confirmed the importance of factors already known in literature. In our opinion for the purpose of better understanding all factors supporting success of gaming projects in crowdfunding platforms could be summed up in three main groups: psychological factors, technological factors, and financial factors.

Using crowdfunding platforms to share creative ideas, to search for inspiration and connect with other creative individuals significantly promoted success in gaming projects (Gerber \& Hui, 2012). This transparent production processes that crowdfunding entails can be considered as distinct from those that often accompany the conventional publisher funded model (Smith \& Kilty, 2014). Constant innovation coming from small startups in order to get enough attention in the saturated market reinforces positive effects in this industry (Tschang, 2007). Creation of the environment favorable for the proper project development refers to encouraging talented people with a clear vision to work on their own ideas, change the traditional method of financing and focus on strategic planning (Milutinovic, Stosic, \& Mihic, 2015). It can be therefore concluded that creativity and innovation from small indie companies, in both new gaming platforms and game software, are one of the driving forces behind success in the game development industry (Kultima \& Alha, 2010).

The development in informational technologies using popular web platforms such as Unity.com provided free of charge valuable development tools for new entries, accompanied with Udemy.com as a contemporary learning platform, providing learning materials at exceptionally low prices. Unity.com as a cross-platform game engine has a vision to "democratize" game development by making it accessible to more developers. Steam platform, as the largest digital distribution platform for PC gaming, is aiming at providing the best medium for distribution and sales of various indie video games. Furthermore, Gaming Forums such as Reddit, IGN Boards, ResetEra, Nintendo Life Forums, Game Revolution etc. provide a great digital foundation for discussions and exploring new possibilities in gaming business. Every company needs to be ready to learn and innovate. Companies and leaders need to balance the efficiency of the information flow design with the effectiveness of the information exchange and carefully design their networks to enable appropriate balance between information flow network efficiency and effectiveness (Petkovic, Aleksic Miric, \& Cudanov, 2014).

Crowdfunding is a valuable alternative to traditional banking funding which supports small creators to develop their ideas. As a reward-based system, supporters are not motivated by financial gain which reduces 
risk of loss for creators. Furthermore, positive funding on a crowdfunding platform could serve as predictor of future demand of the production and may promote future funding through traditional funding channels (Belleflamme, Omrani, \& Peitz, 2015).

More research is needed to better understand the elements which played a dominant role in success of gaming development projects on Kickstarted.com platform. We believe that the synergy of factors such as lucrative industry with significant growth potential, flexibility in rewarding models, an increasing number of creative individuals in the gaming world, interactive communication between developers and backers and easier access to software and distribution channels contributed to these results.

With this work we wanted to point out the expansion of alternative financing in gaming industry, understood by many funders on crowdfunding platforms as one of important perquisites for the future success. It is not clear in which way it will develop in the future, but it will surely remain one of the fast-growing industries in the modern world.

The key limitation of this study is the focus on projects and methodology from one crowdfunding platform Kickstarter.com. the comparative analysis of various platforms would provide additional valuable information on this topic. We would also like to point out a potential limitation of methodology, since all projects in boarding and video games are treated as gaming projects, which might skyed our results. Furthermore, all projects in the gaming segment were treated as indie development projects which cannot always be true. There could be some number of AAA companies testing their own development on the crowdfunding market. Lastly, the time period we analyzed is relatively short. However, since we are working with ca. 150.000 cases and all trends are pretty constant, this fact should not affect our results dramatically.

\section{Conclusion}

Over the last decades the gaming industry has become a major part of the entertainment sector featuring constant growth and innovation. With this study we wanted to present a dramatical expansion of independent game-development companies supported by crowdfunding platforms and the excellent performance they achieved.

The key finding of his study are the statistically significant, robust, and persistently higher odds in game development projects being successfully financed via a crowdfunding campaign, compared to projects not related to gaming development. Promising game projects were supported by three times more backers on average and attained almost as double funds as other projects, while still sporting more modest pledged amounts per backer.

More research is needed to better understand the key factors responsible for success of gaming development projects in comparison with projects in other branches financed via Kickstarter.com. In our opinion, all factors could be summed up in three main groups: psychological factors, technological factors, and financial factors. It is also important to stress the increase in web platforms for development, learning and distribution providing free of charge valuable tools for new entries. It is probably the synergy of lucrative industry with significant growth potential, flexibility in rewarding models, increasing number of creative individuals in the gaming world, interactive communication between developers and backers and easier access to software and distribution channels which contributed to these results.

Furthermore, positive funding on a crowdfunding platform could serve as predictor of future demand of the production and may promote future funding through traditional funding channels. These findings support the notion of crowdfunding being a viable modality of financing independent game development in emerging economies. It is not clear in which way it will develop in the future, but it will surely remain one of the fast-growing industries in the modern world.

\section{REFERENCES}

[1] Belleflamme, P., Omrani, N., \& Peitz, M. (2015). The economics of crowdfunding platforms. Information Economics and Policy, 33(1), 11-28. DOI:10.1016/j.infoecopol.2015.08.003

[2] Bosch, J., \& Sijtsema, P. (2010). From integration to composition: On the impact of software product lines, global development and ecosystems. Journal of Systems and Software, 83(1), 67-76. DOI:10.1016/j.jss.2009.06.051

[3] Bouncken, R. B., Komorek, M., \& Kraus, S. (2015). Crowdfunding: The Current State Of Research. International Business and Economics Research Journal, 14(3), 407-416. DOI:10.19030/iber.v14i3.9206

[4] Businesswire. (2021). Game developers conference, State of the Industry. Retrieved from https://www.businesswire.com/news/home/20210428005374/en/Game-DevelopersConference\%E2\%80\%99s-2021-State-of-the-Industry-Survey-Shows-Pandemic-Brought-Delays---ButAlso-Growth-Reflects-Rising-Interest-in-the-PlayStation-5-and-Strong-Disapproval-of-30-Digi 
[5] Capon, N., Farley, J., \& Hoenig, S. (1990). Determinants of Financial Performance: A MetaAnalysis. Management Science, 36(10), 1137-1292. DOI:10.1287/mnsc.36.10.1143

[6] Computer Hope. (2017). Indie game. Retrieved from https://www.computerhope.com/jargon/i/indiegame.htm

[7] Crowdfunding Market. (2020). Global Crowdfunding Market Research Report. Retrieved from https://www.marketdataforecast.com/market-reports/crowdfunding-market

[8] Devaraj, S., \& Patel, P. C. (2016). Influence of number of backers, goal amount, and project duration on meeting funding goals of crowdfunding projects. Economics Bulletin, 36(2), 12421249.

[9] Du, Z., Li, M., \& Wanga, K. (2019). "The more options, the better?" Investigating the impact of the number of options on backers' decisions in reward-based crowdfunding projects. Information \& Management, 56(3), 429-444. DOI:10.1016/j.im.2018.08.003

[10] Engelstätter, B., \& Ward, M. R. (2016). Strategic Timing of Entry: Evidence from Video Games. Journal of Cultural Economics, 42(1), 1-22. DOI:10.1007/s10824-016-9276-7

[11] European Foundation for Quality Management. (2021). European Foundation for Quality Management. Retrieved from https://www.efqm.org/

[12] Feijoo, C., Gomez-Barroso, J.-L., Aguado, J.-M., \& Ramos, S. (2012). Mobile gaming: Industry challenges and policy implications. The International Journal of Digital Economy, Data Sciences and New Media, 36(3), 212-221. DOI:10.1016/j.telpol.2011.12.004

[13] Franceschini, F., Galetto, M., \& Maisano, D. (2007). Management by Measurement: Designing Key Indicators and Performance Measurement Systems. Springer-Verlag Berlin Heidelberg.

[14] Gerber, E. M., \& Hui, J. S.-Y. (2012). Crowdfunding: Why People Are Motivated to Post and Fund Projects on Crowdfunding Platforms. Northwestern University, Evanston, USA.

[15] Hadzinsky, C. (2014). A Look into the Industry of Video Games Past, Present, and Yet to Come. Claremont McKenna College (Bachelor of Arts Thesis).

[16] Indie to indie games. (2020). Steam game trends in 2020. Retrieved from https://www.intoindiegames.com/steam-game-trends-in-2020-covid-and-the-rise-of-indie-games/

[17] Kaplan, R., \& Norton, D. (1996). The Balanced Scorecard - Measures That Drive Performance. Harvard Business Review, 70(1), 71-79.

[18] Kickstarter. (2021). What-are-the-basics? Retrieved from https://help.kickstarter.com/

[19] King, D. H., Delfabbro, P. H., Billeux, J., \& Potenza, M. N. (2021). Problematic online gaming and the COVID-19 pandemic. Journal of Behavioral Addictions, 9(2), 184-186. DOI:10.1556/2006.2020.00016

[20] Kultima, A., \& Alha, K. (2010). "Hopefully everything I'm doing has to do with innovation": Games industry professionals on innovation in 2009. Paper presented at the 2010 2nd International IEEE Consumer Electronics Society's Games Innovations Conference.

[21] Kuppuswamy, V., \& Bayus, B. L. (2013). Crowdfunding creative ideas: the dynamics of project backers in Kickstarter. In The Economics of Crowdfunding (pp. 151-182). Palgrave Macmillan, Cham.

[22] Lambert, D. M., \& Burduroglu, R. (2021). Measuring and Selling the Value of Logistics. The International Journal of Logistics Management, 11(1), 1-18. DOI:10.1108/09574090010806038

[23] Lax, A. (2017). The Success Factors of Game Industry Crowdfunding Campaigns (Master's Thesis). University of Jyväskylä, Finland.

[24] Lee, C. H., \& Chiravuri, A. (2019). Dealing with initial success versus failure in crowdfunding market. Internet Research, 29(5), 1190-1212. DOI:10.1108/INTR-03-2018-0132

[25] Lin, D., Bezemer, C. P., \& Hassan, E. A. (2017). Studying the urgent updates of popular games on the Steam platform. Empirical Software Engineering, 22(1), 2095-2126. DOI:10.1007/s10664-0169480-2

[26] Malcom Baldrige Quality Award. (2021). Baldrige-award. Retrieved from https://www.nist.gov/baldrige/baldrige-award

[27] Maximumgames. (2016). Behind the scenes: What do game publishers do? Retrieved from https://www.maximumgames.com/press/behind-scenes-game-publishers/

[28] Milutinovic, R., Stosic, B., \& Mihic, M. (2015). Concepts And Importance of Strategic Innovation in SMEs: Evidence from Serbia. Journal of Sustainable Business Management Solutions in Emerging Economies, 20(77), 35-42. DOI:10.7595/management.fon.2015.0030

[29] Nuciarelli, A., Li, F., \& Fernandes, K. J. (2016). From value chains to technological platforms: The effects of crowdfunding in the digital game industry. Journal of Business Research, 78(1), 341-352. DOI:10.1016/j.jbusres.2016.12.030 
[30] Nyitray, K. J. (2011). William Alfred Higinbotham: Scientist, Activist, and Computer Game Pioneer. Retrieved from https://muse.jhu.edu/article/449252/summary

[31] Performance Based Management Special Interest Group. (2001). Analyzing, Reviewing and Reporting Performance Data.

[32] Petkovic, M., Aleksic Miric, A., \& Cudanov, M. (2014). Designing a Learning Network Organization. Journal of Sustainable Business and Management Solutions in Emerging Economies, 73(1), 17-24. DOI:10.7595/management.fon.2014.0029

[33] Roma, P., Petruzzelli, A. M., \& Perrone, G. (2017). From the crowd to the market: The role of reward-based crowdfunding performance in attracting professional investors. Research Policy, 46(9), 1606-1628. DOI:10.1016/j.respol.2017.07.012

[34] Smith, R., \& Kilty, L. A. (2014). Crowdsourcing and Gamification of Enterprise Meeting Software Quality. Paper presented at the IEEE International Conference on Utility and Cloud Computing (UCC).

[35] Statista. (2021). Video Gaming industry 2021. Retrieved from https://www.statista.com/

[36] Tschang, F. T. (2007). Balancing the Tensions Between Rationalization and Creativity in the Video Games Industry. Organization Science, 18(6), 989-1005. DOI:10.1287/orsc.1070.0299

[37] Williams, D. (2009). Structure and Competition in the U.S. Home Video Game Industry. International Journal on Media Management, 4(1), 41-54. DOI:10.1080/14241270209389979

[38] Zhu, L. (2021). The psychology behind video games during COVID-19 pandemic: A case study of Animal Crossing: New Horizons. Human Behavior and Emerging Technologies, 3(1), 157-159. DOI:10.1002/hbe2.221

Received: 2021-07-04

Revision requested: 2021-08-17

Revised: 2021-08-21

Accepted: 2021-09-11

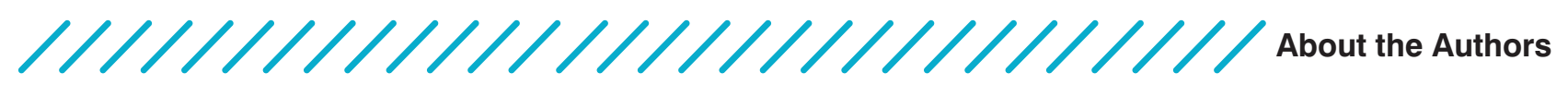

Dana R. Stojiljković

University of Belgrade, Faculty of Organizational Sciences, Serbia dana.stojiljkovic@yahoo.com

Dana Stojiljkovic is a PhD candidate at the Faculty of Organizational Sciences, University of Belgrade. Currently employed in Volkswagen Group Services Ltd. in Emden, Germany as Production and Finance Controller. Her research interests focus on Finance Management, Production Performance Indicators and Quantitative Analytics.

$$
\begin{array}{r}
\text { Marko Mihić } \\
\text { University of Belgrade, Faculty of Organizational Sciences, Serbia } \\
\text { marko.minic@fon.bg.ac.rs }
\end{array}
$$

Marko Mihic is a Full Professor and Head of Department of Management and Project Management at the Faculty of Organizational Sciences, University of Belgrade. $\mathrm{He}$ is a Director of the Centre for professional certification of managers at the Faculty of Organizational Sciences and a Managing partner at the Serbian Management Centre. He is also one of the founders of the Centre for Microsoft Project established in cooperation with Microsoft Serbia, Certified Lecturer in Strategic Management and

Leadership at The Chartered Management Institute and member of the following professional institutions: Academy of Management and Project Management Institute. His research interest includes Project Management, Strategic Management, Cost-Benefit Analysis, Change Management and Leadership. As an expert consultant, he has worked extensively for the Serbian government institutions, as well as for several leading national and multinational companies and investors in Serbia and the Balkan region.
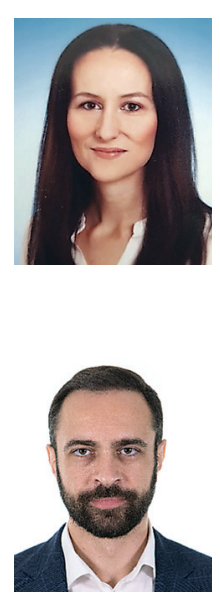


\section{Dragan Bjelica}

University of Belgrade, Faculty of Organizational Sciences, Serbia dragan.bjelica@fon.bg.ac.rs

Dragan Bjelica is an Assistant Professor at the Faculty of Organizational Sciences, University of Belgrade with research interests in project management, strategic management, preparation, and evaluation of investment projects. He holds the most prestigious Project management certifications, issued by the Project Management Institute: Project Management Professional (PMP) and Agile Certified Practitioner (PMIACP). Currently, he is a Head of the Project Management Centre at the Faculty of

Organizational Sciences, University of Belgrade. He was a lecturer in over 50 educational programmes and expert seminars in the implementation of project management software and taken part in the implementation of over 20 scientific and commercial projects in the field of management in Serbia and abroad. He has published over 70 scientific papers, peer-reviewed conferences and journals, three chapters in monographs, as well as one monograph under the title "Agile project management". 